\title{
Double-blind trial of amoxycillin and ampicillin plus probenecid in the treatment of gonorrhoea in men
}

\author{
A. R. BRATHWAITE \\ From the Comprehensive Health Centre, Kingston, Jamaica
}

SUMMARY In a double-blind study amoxycillin $3 \mathrm{~g}$ or ampicillin $3 \mathrm{~g}$ plus probenecid $1 \mathrm{~g}$ were randomly administered as a single oral dose to 160 men with uncomplicated gonococcal urethritis. The cure rate for each drug group was $\mathbf{9 8 . 6 \%}$. Tolerance to oral medication was good and no evidence of allergy or toxicity to either drug was shown. No case of post-gonococcal urethritis was observed over a 14-day follow-up period. Thus, both drug regimens proved very effective in treating uncomplicated gonococcal urethritis in men.

\section{Introduction}

Amoxycillin is an acid-stable, semisynthetic penicillin which is closely related to ampicillin having a similar antibacterial spectrum and level of activity (Sutherland and Rolinson, 1971; Sutherland et al., 1972). When taken orally amoxycillin is better absorbed, and mean peak serum concentrations at two hours are twice those of an equivalent dose of ampicillin (Croydon and Sutherland, 1970). Amoxycillin is not converted into ampicillin in the body.

Several trials using both amoxycillin and ampicillin in the treatment of uncomplicated gonorrhoea have been reported (for example, Karney et al., 1974). No such studies, however, have been reported from the Caribbean area. For this reason a double-blind study was conducted to compare the efficacy of ampicillin $3 \mathrm{~g}$ plus probenecid $1 \mathrm{~g}$ with amoxycillin $3 \mathrm{~g}$, since the latter had been shown to give the best results.

\section{Patients and methods}

Men with uncomplicated gonorrhoea attending the sexually transmitted diseases section of the Comprehensive Health Centre during the period October to December 1977 were admitted to the study. A presumptive diagnosis was made by microscopical identification of typical Gram-

Address for reprints: Dr A. R. Brathwaite, Comprehensive Health Centre, 55 Slipe Pen Road, Kingston 5, Jamaica, West Indies

Received for publication 17 October 1978 negative intracellular diplococci in smear specimens taken from the urethra. At the same time, material for culture was plated on Thayer-Martin (VCN) media and incubated immediately in candleextinction jars at $37^{\circ} \mathrm{C}$. These were examined for oxidase-positive colonies after 24 and 48 hours' incubation. Gram-stains from typical colonies were examined microscopically.

Patients were then each given a packet of medication containing six 500-mg capsules of either ampicillin plus probenecid or amoxycillin plus placebo tablets to take under direct supervision of a senior member of the clinic staff. The drugs had been coded in random order and prepacked by the manufacturers in identical white capsules, placebo probenecid tablets being used with the amoxycillin. The coding used was unknown to the clinic staff. Patients who were allergic to penicillin, or who were unlikely to attend for follow-up, were excluded from the trial.

Patients were advised to refrain from sexual intercourse and to return to the clinic three, seven, and 14 days after treatment. At each visit, they were questioned about symptoms and sexual contacts and the original instructions were repeated. Gram stains and cultures were also repeated as performed at the first visit.

Treatment was considered to have failed if presumptive gonococci were found in smears and cultures within 14 days in patients who denied further sexual intercourse. Patients were considered to be reinfected if gonococci were found and sexual intercourse admitted to during this follow-up period.

Post-gonococcal urethritis (PGU) was diagnosed if 
a urethral discharge containing at least 10 leucocytes per field on microscopy using a $\times 100$ objective was present.

\section{Results}

Eighty patients were treated with each regimen. Their age range was similar to that of patients with gonorrhoea seen routinely at the clinic (Table 1).

Table 1 Ages (in years) of the two treatment groups

\begin{tabular}{lllll}
\hline Drug regimen & Mean & Median & Mode & Range \\
\hline Amoxycillin & $27 \cdot 6$ & $24 \cdot 2$ & 23 & $16-77$ \\
$\begin{array}{l}\text { Ampicillin plus } \\
\text { probenecid }\end{array}$ & $26 \cdot 2$ & $24 \cdot 2$ & 20 & $16-48$ \\
\hline
\end{tabular}

They were all negroes in the lower socioeconomic class. Four patients in the group treated with amoxycillin and two in the group treated with ampicillin and probenecid were married; the remaining patients were single. The mean number of sexual partners in the preceding month was 1.5 and 1.7 in the former and latter groups respectively.

Of those patients treated with ampicillin $3 \mathrm{~g}$ plus probenecid $1 \mathrm{~g}, 71(98 \cdot 6 \%)$ of 72 patients who were followed up for 14 days were cured. Seven patients were reinfected and one defaulted in this group (Table 2).

Of those patients treated with amoxycillin $3 \mathrm{~g}, 71$ $(98 \cdot 6 \%)$ of 72 patients who were followed up for 14 days were cured. Six patients were reinfected and two defaulted (Table 2).

Of the 13 patients with reinfections all had negative results to tests for gonococci on the third day (Table 3). On the seventh day, eight patients had positive results, four results remained negative, and one patient defaulted. By the 14th day, the four patients who had had negative results and the one who had failed to attend previously all had positive culture results. All admitted to re-exposure to infection.

By contrast, both patients in whom treatment failed had positive results to investigations taken on the third day. The results of one patient remained positive on the seventh day when he was removed from the study. The other patient who did not attend for follow up on the seventh day had a positive result when he attended on the 14th day. Both these patients had minimal symptoms (Table 3 ).

No case of PGU was identified during the 14-day follow-up period.

Table 3 Follow-up results in 15 cases of failure/reinfection

\begin{tabular}{lccc}
\hline & \multicolumn{3}{l}{ Follow-up period (days) } \\
\cline { 2 - 4 } Results & 3 & 7 & 14 \\
\hline Positive & 2 & $9^{*}$ & $6^{*}$ \\
Negative & 13 & 4 & 0 \\
Removed from study & 0 & 0 & $9^{*}$ \\
Defaulted from visit & 0 & $2^{*}$ & 0 \\
Total & 15 & 15 & 15 \\
\hline
\end{tabular}

*One treatment failure

\section{Discussion}

Although, for technical reasons, it was not possible to perform antibiotic sensitivity tests on gonococcal strains isolated in this study, the cure rate of $98.6 \%$ with either regimen is very satisfactory when it is remembered that in $197174 \%$ of strains isolated at this clinic gave minimum inhibitory concentrations of penicillin of $0.1 \mathrm{unit} / \mathrm{ml}$ and over (Fleming et al., 1974). These results are comparable to some obtained from areas with a much lower incidence of less sensitive strains. Alergant (1973) reported a cure rate of $94 \cdot 2 \%$ with amoxycillin $1 \mathrm{~g}$ plus probenecid $1 \mathrm{~g}$ in Liverpool; Willcox (1974), in London, obtained a cure rate of $98 \cdot 8 \%$ using amoxycillin $3 \mathrm{~g}$ in two oral doses five hours apart; Karney et al. (1974) had a cure rate of $95 \%$ with amoxycillin $3 \mathrm{~g}$ and of $98 \%$ with ampicillin $3.5 \mathrm{~g}$ plus probenecid $1 \mathrm{~g}$ in Seattle; Deal et al. (1974), in Florida, reported a 97\% cure rate with amoxycillin $3 \mathrm{~g}$; Gurwith et al. (1974) using amoxycillin $3 \mathrm{~g}$ and $2 \mathrm{~g}$ plus probenecid $0.5 \mathrm{~g}$ obtained cure rates of $95 \cdot 4 \%$ and $89 \cdot 5 \%$ respectively in Manitoba; Roberts (1974) obtained rates of $84 \%$ and $95 \%$ using amoxycillin $1 \mathrm{~g}$ and $3 \mathrm{~g}$ respectively in Tennessee; and Wolk (1974), in California, claimed a cure rate of $94 \%$ in men using amoxycillin $3 \mathrm{~g}$.

Lassus et al. (1975), in Helsinki, had a cure rate of $100 \%$ with amoxycillin $3 \mathrm{~g}$ if the two possible reinfections are excluded. In London, Price and Fluker (1975) using amoxycillin $3 \mathrm{~g}$ obtained a cure

Table 2 Results of the two treatment regimens in patients followed up for 14 days

\begin{tabular}{|c|c|c|c|c|c|c|c|c|c|c|}
\hline \multirow[b]{2}{*}{ Drug regimen } & \multicolumn{2}{|c|}{ Cure. } & \multicolumn{2}{|c|}{ Failure } & \multicolumn{2}{|c|}{ Reinfection } & \multicolumn{2}{|c|}{ Defaulted } & \multicolumn{2}{|c|}{ Total } \\
\hline & No. & $\%$ & No. & $\%$ & No. & $\%$ & No. & $\%$ & No. & $\%$ \\
\hline $\begin{array}{l}\text { Amoxycillin } 3 \mathrm{~g} \\
\text { Ampicillin } 3 \mathrm{~g}\end{array}$ & 71 & $98 \cdot 6$ & 1 & $1 \cdot 4$ & 6 & & 2 & & 80 & 100 \\
\hline plus probenecid $1 \mathrm{~g}$ & 71 & $98 \cdot 6$ & 1 & $1 \cdot 4$ & 7 & & 1 & & 80 & 100 \\
\hline
\end{tabular}


rate of $99 \%$ in men and $95 \%$ in women assessed at the first follow-up three days later. Thin et al. (1977), in London, in the only double-blind study in this series, claimed cure rates of $86 \%$ and $94 \%$ using amoxycillin $1 \mathrm{~g}$ and $3 \mathrm{~g}$ respectively (both given with probenecid). In all of these studies cure rates were assessed within 14 days of treatment.

The early (upward) part of the blood concentration curve following administration of amoxycillin $3 \mathrm{~g}$ has been shown by Neu (1974) to approximate that following ampicillin $3.5 \mathrm{~g}$ plus probenecid $1 \mathrm{~g}$, but disappearance was faster with amoxycillin. Kvale et al. (1971) claimed a cure rate of $96 \%$ in men treated with ampicillin $3.5 \mathrm{~g}$ plus probenecid $1 \mathrm{~g}$ for acute gonococcal urethritis in the Philippines, an area with a high incidence of strains insensitive to penicillin. Their result is similar to that found by Karney et al. (1974) and to that of the present trial. Whereas Kvale et al. (1971) found a $47.9 \%$ incidence of PGU during a 21-day follow-up period, however, no cases of PGU with either regimen were seen in this trial at 14 days.

Amoxycillin (Amoxil) was kindly supplied by Beecham Pharmaceuticals Ltd. and probenecid (Benemid) by Merck Sharp and Dohme Ltd. The help of Mr Paul Gordon and Mrs Enid Miller, of the staff of the Comprehensive Health Centre, is gratefully acknowledged.

\section{References}

Alergant, C. D. (1973). Treatment of gonorrhoea with amoxycillin. British Journal of Venereal Diseases, 49, 274-276.
Croydon, E. A. and Sutherland, R. (1970). $\alpha$-amino-p-hydroxybenzylpenicillin (BRL 2333), a new semisynthetic penicillin: absorption and excretion in man. Antimicrobial Agents and Chemotherapy, 10, 427-430.

Deal, W. B., Polly, S. M., and Zellner, S. R. (1974). Therapy of uncomplicated gonococcal urethritis in the male with a single dose of amoxycillin. Journal of Infectious Diseases, 129 (June Suppl.), 256.

Fleming, W. L., Brathwaite, A. R., Martin, J. E., and Collier, J. (1974). Penicillin and tetracycline sensitivity of Jamaican strain of gonococci. West Indian Medical Journal, 23, 226.

Gurwith, M. J., McGinnis, S., Ronald, A. R., and Henry, R. (1974). Treatment of uncomplicated gonorrhoea in women with a single oral dose of amoxycillin. Journal of Infectious Diseases, 129 (June Suppl.), 258.

Karney, W. W., Turck, M., and Holmes, K. K. (1974). Single-dose oral therapy for uncomplicated gonorrhoea: comparison of amoxycillin and ampicillin given with and without probenecid. Journal of Infectious Diseases, 129 (June Suppl.), 250.

Kvale, P. A., Keys, T. F., Johnson, D. W., and Holmes, K. K (1971). Single oral dose ampicillin-probenecid treatment of gonorrhoea in the male. Journal of the American Medical Association, 215, 1449.

Lassus, A., Renkonen, O-V., and Rostila, T. (1975). Treatment of uncomplicated gonorrhoea with a single dose of amoxycillin. Chemotherapy, 3, 127.

Neu, H. C. (1974). Antimicrobial activity and human pharmacology of amoxycillin. Journal of Infectious Diseases, 129 (June Suppl.), 123.

Price, J. D. and Fluker, J. L. (1975). Amoxycillin in the treatment of gonorrhoea. British Journal of Venereal Diseases, 51, 398-400.

Roberts, F. L. (1974). Treatment of uncomplicated gonorrhoea with amoxycillin. Journal of Infectious Diseases, 129 (June Suppl.), 262.

Sutherland, R and Rolinson, G. N. (1971), $\alpha$-amino-p-hydroxybenzylpenicillin (BRL 2333), a new semisynthetic penicillin: in vitro evaluation. Antimicrobial Agents and Chemotherapy, 1970 411.

Sutherland, R., Croydon, E. A. P., and Rolinson, G. N. (1972) Amoxycillin: a new semi-synthetic penicillin. British Medical Journal, 3, 13-16.

Thin, R. N., Symonds, M. A. E., Shaw, E. J., Wong, J. Hopper, P. K., and Slocombe, B. (1977). A double-blind trial of amoxycillin in the treatment of gonorrhoea. British Journal of Venereal Diseases, 53, 118-120.

Willcox, R. R. (1974). Effective treatment of gonorrhoea in London with two oral doses of amoxycillin. British Journal of Venereal Diseases, 50, 120-124.

Wolk, E. (1974). Amoxycillin in the treatment of uncomplicated gonococcal urethritis in males. Journal of Infectious Diseases, 129 (June Suppl.), 264. 